\title{
KNOWLEDGE OF OSTEOPOROSIS AMONG MEN ATTENDING PRIMARY CARE CLINIC AND THE ASSOCIATED FACTORS
}

\author{
Suhaiza Samsudin ${ }^{1}$, Syahnaz Mohd Hashim ${ }^{2}$ and Azmawati Nawi ${ }^{3}$ \\ ${ }^{1}$ Department of Family Medicine IIUM, ${ }^{2}$ Department of Family Medicine UKM, \\ ${ }^{3}$ Department of Community Health UKM
}

Presenter: Suhaiza, shaiza@iium.edu.my

Introduction: Osteoporosis has frequently been regards as a disease of women only. However, men are also at risk of developing osteoporosis. We aimed to evaluate the knowledge of osteoporosis among men and its associated factors.

Materials and method: A cross-sectional study of 245 male patients aged 50 and above was conducted in the primary care clinic, University Kebangsaan Malaysia Medical Centre. The research instrument used in this study was a validated self-administered questionnaire which consists of socio-demographic data and 16 items of knowledge of osteoporosis among men.

Results: The mean score for knowledge was $7.78 \pm 3.32$ out of 16 points. Most of the subjects ( 83 percent) knew the definition of osteoporosis but were not aware that osteoporosis was a silent disease. Only a quarter of subjects (38 percent) recognized family history as a risk factors for osteoporosis. Despite 78 percent of subjects answer correctly regarding importance of calcium intake in their diet however only 7 percent of them knew the recommended dosage of daily calcium intake. Knowledge of osteoporosis was found to be significantly associated with education and total monthly household income.

Conclusion: Findings indicate limited knowledge of osteoporosis among the subjects. Public education of osteoporosis among men is important to increase their knowledge. Meanwhile, primary care doctors should also emphasize and educate men regarding osteoporosis to enhance their knowledge of the disease. 